\title{
ASSESSMENT AND ANALYSIS FOR SUSTAINABLE GROWTH AND DEVELOPMENT OF TOURISM AND TOURIST FACILITIES IN KASHMIR
}

\author{
Moazam Iqbal ${ }^{1}$ \\ ${ }^{I}$ Department of Civil Engineering, DIT University, Dehradun, India
}

\begin{abstract}
Present advancement in field of science and technology has accelerated worldwide growth and progressive development manifold. It is inevitable today for any community or region to explore all its resources and use them optimally for maximum revenue generation and employability. To cater for long-lasting benefits and meeting future needs; adopted expansion model needs to be not merely convincing but also sustainable. In this study a detailed analysis and comparison is drawn between sustainable development and its applicability specifically towards Tourism industry-particularly in context of Kashmir valley. While the region is going for large-scale development in terms of expansion of infrastructure and technology, negative implications of faulty or ill planning and policy deficits in mega tourism related projects needs to be measured prudently. Considering the fragile eco-system of Kashmir valley, any strategy for expansion of facilities needs to be carefully analyzed and logically planned for an effective and ecologically stable long lasting operation. This study highlights some critical aspects for augmentation of existing tourism grid within the region specifically giving attention to sustainable development model for planning and at the same time endorsing some indispensable scientific recommendations for implementation in order to achieve Kashmir (often regarded as paradise on earth) as a rationalized world class traveler friendly and economically viable \& sustainable tourist destination for years to come.
\end{abstract}

Keywords: Kashmir, Sustainability, Eco-System, Flora \& Fauna, Landscapes

$* * *$

\section{INTRODUCTION}

With Tourism contributing to about $7.5 \%$ of India's Gross Domestic Product (GDP) at about 2.5 lakh crores of rupees and contributing to about $6.98 \%$ of Gross State Domestic Product (GSDP) of J\&K State, tourism is one of the most promising sectors for employment generation in the state [1]. Kashmir valley with an area of 5,992.4 sq mi is gifted by nature with pristine natural beauty and paramount splendor. Divided by Himalyan mountain range from Ladakh region on north-east and separated by Pir Panjal range from rest of India, Kashmir valley offers unique blend of rich heritage and picturesque landscapes to its visitors. Innumerable and varied species of flora \& fauna make this place exclusive and a major source of attraction globally. Owing to its unaltered sceneries and unexplored terrains it has been able to attract tourists worldwide over years.

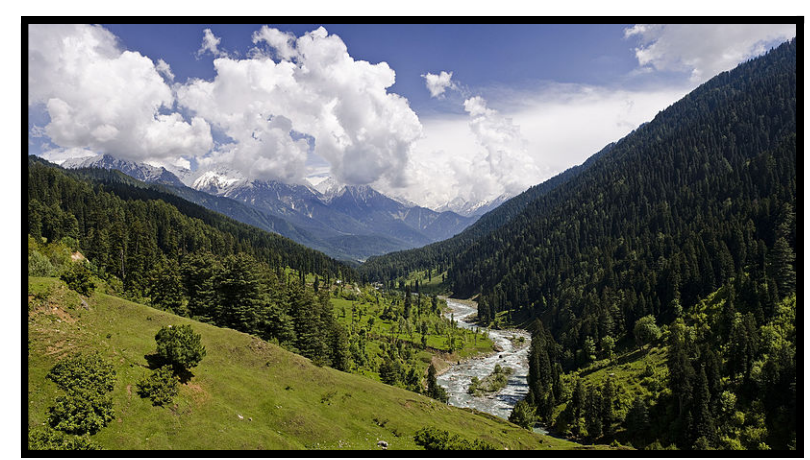

Pahalgam- Kashmir Valley [Source- Internet]

\section{PRESENT SCENARIO}

Kashmir valley has been gifted with varied landscapes from north to south which are known to bring amazement to travellers. While many of such regions have been adopted for development, most of the areas remain unexplored and unattended. Among the popular destinations like Gulmarg, Pahalgam, Sonamarg, Parts of Srinagar city etc most tourist destinations have either overflown their capacities based on existing infrastructure or are undergoing massive unplanned and unorganized expansions. Prominent destinations like Gulmarg and Pahalgam have over years been encroached illegally or plundered off their wealth in terms of natural and unaltered beauty. Government apathy and callous attitude laden with blemished planning has led to further deterioration. Uncontrolled human interventions like uncontrolled use of concrete in structures lacking proper sewage disposal or waste management system are further ruining unique identity and rich flora \& fauna of tourist resorts of Kashmir. Additionally, use of plastic and high emission fuels like coal, wood, diesel etc. further leads to drastic melting of glaciers in the vicinity causing serious damages to natural processes and causing irreversible loss to overall tourism worth of the place. Cumulative effects of all this are negative consequences in terms of degraded natural environment and diminishing tourism capability of region as a long term sustainable and viable tourism venture. 


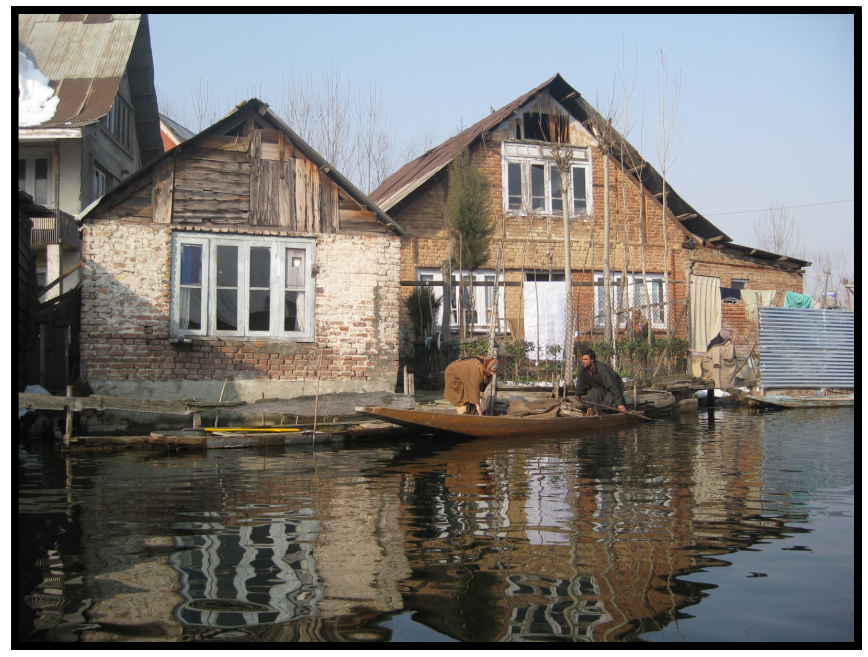

Cement Houses in interior of Dal Lake [5]

\section{SUSTAINABLE DEVELOPMENT MODELS}

\section{a) Eco-Tourism}

Focusing primarily on promotion of natural environs as primary attractions, eco-tourism concept focuses on projection of cultural heritage in natural environment with least effect on original characteristics of region and at the same time instilling a sense of belonging among travellers. Eco tourism is a holistic approach and provides best alternative for any government agency to transfer implementation of sustainable development programs onto the stakeholders like hoteliers etc. and end users like tourists. Considered as fastest growing market in tourism industry with a growth rate of 5\% annually; eco-tourism concept is best possible conservation/ management practice with opportunities of growth [2]. It can best be used to match varying needs of tourists both on budget and high end scale while simultaneously satisfying social, environmental as well as economic needs.

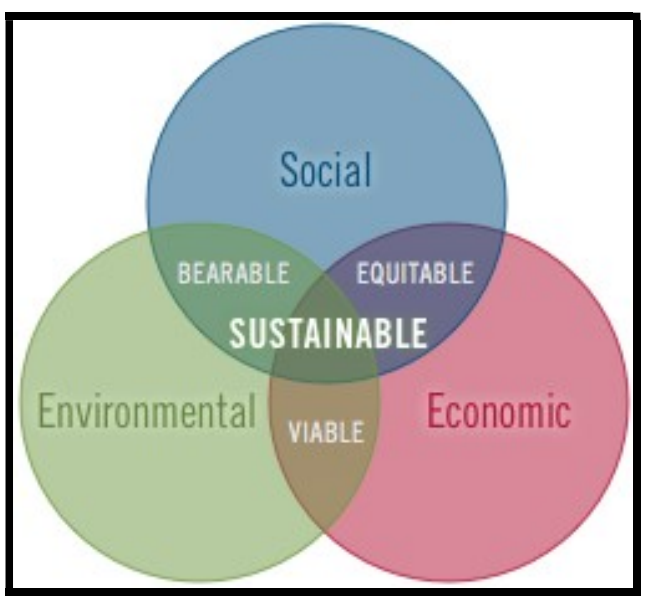

Sustainability Diagram for Eco-Tourism Concept.

\section{b) Green Building Technique's}

Green building methodology is the most contemporary concept of building environment friendly and utility wise effective structures. It focuses on optimal use of natural resources like sunlight, air, oxygen etc. The most unique feature of these buildings is the use of non-toxic and nonpolluting materials available locally. With small scale sewage treatment plants and in-house solar power generation units, these buildings function as self-sufficient entities with almost zero levels of harmful emissions. Furthermore, this concept involves reuse of waste water for convenience purposes like flushing, gardening, cleaning etc. Use of eco-friendly materials in construction of green buildings helps in bringing down pollution levels drastically which otherwise prove detrimental for any prevailing ecosystem. With smart use of natural resources like sunlight and air, heavy cost cutting measures can be implemented in terms of savings on account of heating, lighting or air conditioning cost for guest rooms. With almost zero emissions and usage of non-littering materials, green buildings concept is essential for any tourist destination for providing world class facilities to its guests and at the same time nurture conservation and promote its natural resemblance to attract maximum tourists.

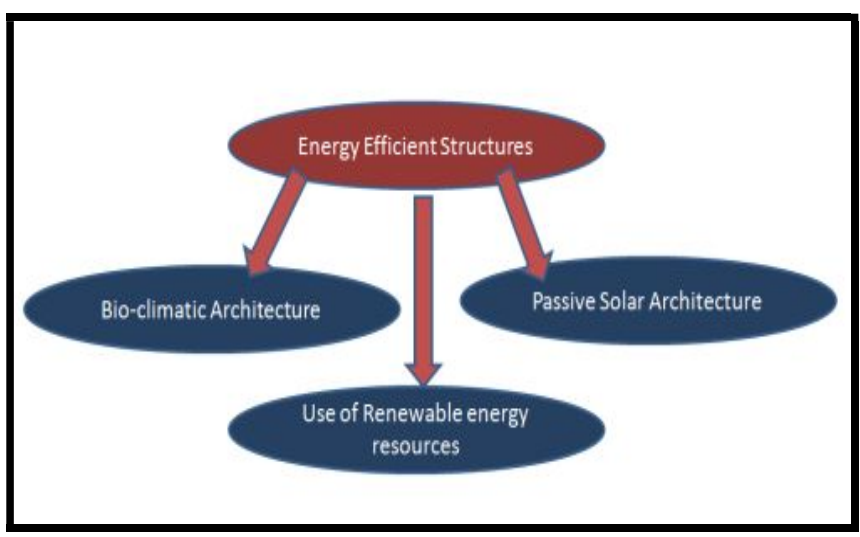

Green Building Features

\section{c) Buffer Zones}

In order to promote conservation of natural environ of any region it is essential to prevent human interventions like constructions, pollution, garbage etc. in vicinity of region with tourism potential. This needs to be done in order to prevent damage and stress on beautiful landscapes of area which can prove to be detrimental for sustainability of region as a tourist attraction. This concept of designating 'Buffer Zones' in tourism industry can be considered similar to one adopted in case of wildlife reserves and national parks whereby a certain region is provided to wildlife species to thrive and multiply freely. Such regions in field of tourism related activities ensure minimum adverse consequences on natural flora \& fauna which otherwise are a major attraction among visitors.

Buffer zones, at distances ranging between 8-10 kilometers from region of actual interest are beneficial not only from environmental aspects but also promote planned development of accommodations for tourists. International standard hotels with five star facilities for high end tourists which otherwise require vast area and discharge massive emissions could thus be made available in phased manner due to effectual planning and expansion strategy for 
maximum sustainability and revenue generation at suitable distance from fragile eco-zones of tourist importance.

Buffer zones also act as future Land Banks for critical infrastructure developments in vicinity of tourist destination. These regions can thus be used in future for augmentation of tourist facilities and up gradation of existing infrastructure without additional financial implications or burdens.

\section{d) Resort Management}

One of the worst problems faced by any tourist destination is lack of coordination among various segments of tourist welfare or tourist benefit facilities available or already in place. For any tourist destination to serve the purpose as a long term economically viable feature it is essential for any controlling agency to ensure coherence and timely augmentation of managerial intellect for a smart management system. In absence of coordination, dilapidation of infrastructure and in compensable harm to reputation of destination is inevitable. Proactive approach and smart strategy to channelize running of various facilities with use modern technological features is the most distinct and innovative method to achieve traveller satisfaction along with sustainability. Resort management also includes effective enforcement of laws and strict exemplary punishment to offenders of any kind.

Monitoring of land use and development works through smart vigil and reinforced with hi tech systems like GIS etc can prove pivotal in enforcement of well-planned policies for a smart resort or destination management. Additionally, use of latest technological features like cloud based mobile applications and management software for a simulated notification technology can help tourists better understand about region and give them options to explore more of natural landscapes and topographies with all necessary information required by them. Additionally, it helps controlling bodies to virtually monitor the inflow and satisfaction level among tourists with a proper grievance redressal mechanism in place and at the same time bringing end to monopoly or malpractices.

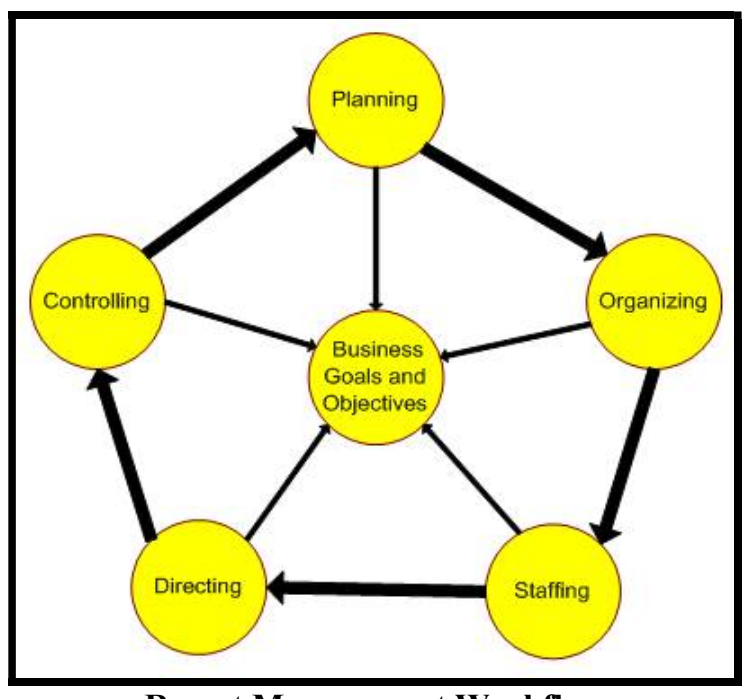

Resort Management Workflow

\section{e) Effective Waste Management}

The biggest challenge for any agency or government body maintaining a destination is of waste disposal and management. This problem becomes enormous especially when a particular destination is far off from landfill site or lacks any other scientific disposal system. Additionally, it becomes necessary to quickly dispose-of or transport waste away from destination before the breakdown of waste material which leads to release of foul odors due to formation of Hydrogen Sulphide and other obnoxious gases. Under such circumstances adoption of waste management strategy or preliminary waste treatment procedures within hours of waste formation becomes inevitable. Waste management system of any tourist destination needs to be streamlined with a dedicated waste disposal system well augmented by proper and covered transportation and further strengthened by time bound and suitable disposal at appropriate distance from tourist destination ensuring zero impairment to natural environment and serene atmosphere. Owing to the magnitude of waste production nowadays, its management system should be mechanized rather than labor intensive for time efficiency. Utmost thrust needs to be laid on sensitizing all stakeholders with concept of waste segregation at source so that its disposal becomes an easy task for concerned organizations later on. Without proper waste management system in place, survival of any tourist destination in its original shape is impossible and practically unmanageable.

\section{APPLICABILTY TO KASHMIR DIVISION}

\section{a) Eco-Tourism}

With respect to varied demands of tourism sector in Kashmir, eco-tourism concept can prove to be a game changer in numerous ways like use of traditional 'Gujjar' (nomad) huts (locally referred as Kotha) along far flung virgin destinations as accommodations projecting diverse cultural varieties of region. These huts presently in abundance along upper belts of entire Kashmir valley specially Pahalgam, Gulmarg, Sonamarg, Yusmarg, Dodpatheri etc are self-sufficient in terms of nominal basic facilities and could be further modernized and brought at par to suit typical needs of a traveller without harming or manipulating the value of precious heritage of Kashmir valley. With a natural touch eco-tourism concept can further connect tourists with rich and diverse cultural heritage of locals and boost tourism with instilling an idea of heritage and conservation among tourists as priority. Also, this can drastically help to bring down use of concrete at tourist destinations by promoting conservationism and help maintain natural appearance of region while simultaneously promoting tourism and heritage. 


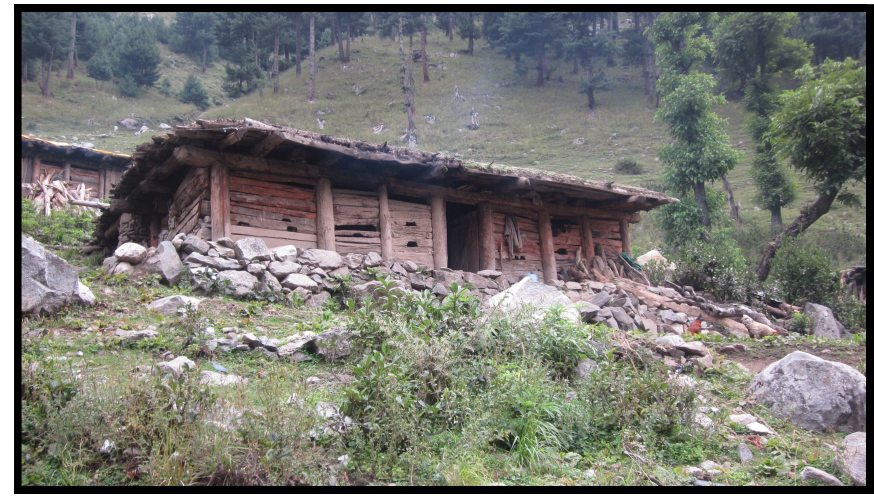

Gujjar Hut or Kotha

\section{b) Green Building Technique's}

Green buildings which are self-sufficient in terms of energy and recycling procedures are best suited for virgin valleys of Kashmir region along regions of Gurez, Lolab, Bungas etc in north Kashmir which are still unexplored and unmarked on tourism maps. Green buildings can be used effectively to provide basic facilities to visitors and help them make their stays in such far off areas a memorable one.

In high tourist density areas like Gulmarg, Pahalgam, Sonamarg etc green buildings shall provide a breakthrough in terms of pollution control and limiting emissions from hotels, guest houses and restaurants within prescribed parameters.

\section{c) Buffer Zones}

Most of the tourist destinations in Kashmir are either overcrowded or have become choked due to unplanned growth of hotels and other facilities. The subsequent uncontrolled pollution becomes unmanageable affair and a major cause of trouble for all. Buffer zones offer opportunities for re-development and re-embodiment of standardized tourist facilities in terms of accommodations by planned and sequential growth at suitable distances from tourist destinations without harming the tourist places. Concept of Buffer Zones for example can be best implemented at Tangmarg in north Kashmir which is adjacent to world famous ski resort of Gulmarg which has already been overcrowded with big and small hotels and huts.

\section{d) Resort Management}

Most of the tourist destinations in Kashmir are managed through Development Authorities who are entrusted with huge government tasks in addition to management of affairs at destination. An effective team of professionals with its smart and modernized technology backend can be entrusted with specific and sole task of providing managerial services like resort management which could help government tap maximum revenue and at the same time ensure growth of Kashmir as an international tourism brand.

\section{e) Effective Waste Management}

Every tourist destination in Kashmir is struggling to cope up with its waste production on daily basis. A proper centralized mechanism with absolute powers for waste management envisaged as a Waste Management Authority needs to be enacted by law and stringent punishment structure for violators needs to be put in place. Also efficient and modernized Sewage Treatment Plants (STP's) need to be procured and installed both on micro scale at hotels, guest houses etc. and also at large scale in synergy with the combined sewage treatment mechanism already present. Dumping and soaking of untreated sewage needs to be discouraged strictly and scientific methodology for waste disposal rather than landfilling or burning should be encouraged with active and mandatory participation of stakeholders.

\section{CONCLUSION}

While a lot needs to be done to modernize tourism industry of Kashmir; correlating the direct impact of environment on tourism needs to be comprehended in order to prioritize this sector and realize its huge potential in generating enormous revenue and jobs in state. Need of hour for tourism in Kashmir is not mere Development but Sustainable Development. With steps like adopting sustainability model, Kashmir with its natural beauty can be portrayed as a yearround self-reliant tourist destination with sustainability and existence as utmost priority.

\section{REFRENCES}

[1] Business Standard Magazine Website - (businessstandard.com)

[2] World Trade Organization report on Global Tourism 2014.

[3] Sustainable and Responsible Tourism: Trends, Practices and Cases, Manhas P.S

[4] Tourism, Biodiversity and Sustainable Development (Across Tourism: Impact In South Asia), Vol. 3 - OP Chandra \& Ashish Chandra.

[5] Managing Sustainable Tourism, David L., Sr. Edgell

[6] The Valley of Kashmir, Sir Walter Roper Lawrence.

\section{ACKNOWLEDGEMENT}

The author acknowledges help from prominent Landscaping expert Mr Fida Iqbal for sharing knowledge and vast experience. Author is also highly thankful to guides and friends at DIT University, Dehradun for continuous motivation and support. 